\title{
DIRECTED ORIENTATION OF STEEL FIBRES IN ULTRA-HIGH-PERFORMANCE CEMENTITIOUS COMPOSITE USING THE MAGNETIC FIELD
}

\author{
ROMANA LOVICHOVÁ, KRISTÝNA TAKÁČOVÁ, KAREN KÜNZEL, VÁCLAV PAPEŽ, \\ MICHAL MÁRA, JINDŘICH FORNU゚SEK, PETR KONRÁD \& RADOSLAV SOVJÁK \\ Czech Technical University, Czech Republic
}

\begin{abstract}
Ultra-high-performance fibre-reinforced cementitious composites are one of the key industries in the field of concrete technology. Thanks to their exceptional mechanical properties and significantly improved ductility, they are widely used for various special applications such as defensive and protective structures. In composite materials, it is desirable to place the reinforcement where it is needed and in the direction it is needed. In fibre-reinforced cementitious composites, this orientation is possible through a magnetic field. In the framework of this study, a prototype device for controlled fibre orientation in a cementitious composite was developed. Mixtures of both cementitious composite and ultrasound gel having similar rheological properties to the cementitious matrix were tested. It has been observed that is possible to control the orientation of the steel fibres and direct the fibres in the desired direction by employing an electromagnetic field.
\end{abstract}

Keywords: cementitious composite, magnetic field, steel fibres, fibre orientation, UHPFRC.

\section{INTRODUCTION}

Due to technological advances and developments in the field of cement and concrete composites, increased usage of ultra-high-performance cementitious composites (UHPC) with enhanced resistance to water penetration, improved toughness and fatigue strength can be expected in the construction sector [1]. Steel fibres in the combination with plain UHPC matrix negate its main disadvantage, which is fragility [1], [2]. Besides, the ultra-highperformance fibre-reinforced concrete (UHPFRC) is a promising material with increased resistance to extreme loads [3], [4]. However, the main concern of this heavily reinforced composite is the issue of fibre dispersion and orientation. Currently, fibres for the design of UHPFRC are considered to be evenly dispersed, which is, in fact, not true. The position and orientation of the fibres are influenced by many parameters such as the formwork shape, the fluidity of the mixture and the filling method [5]-[7]. It follows that it is practically impossible to provide perfect isotropy for such a composite. If the exact position and orientation of the fibres are not known, the resulting mechanical properties of the composite may vary significantly.

The resulting mechanical properties of UHPFRC depend not only on the composition of the cementitious matrix but substantially also on the fibres. Namely on their cross-section and length, shape, the steel they are made of, and also on the fibre dispersion in a cement matrix, fibre volume fraction in the mixture, interaction with cement matrix and last but not least on the fibre orientation. All these parameters must be known and controllable for proper design assessment.

Several attempts have been made for mechanical orientation of fibres [6]-[8]. Also, several studies have been conducted to achieve better dispersion of fibres in concrete [9]. This work aims to determine whether ferromagnetic fibres can be oriented in a matrix of ultra-high-performance cementitious composite by employing a magnetic field. It can be assumed that it is possible to specifically determine the position and direction of 
ferromagnetic steel fibres through a magnetic field. The disperse fibre reinforcement in the composite can be most effectively utilized by placing the fibres in the locations and direction of tensile stress. It is generally accepted, that by controlling the fibre orientation, a composite material with improved performance and decreased cost can be created. Moreover, some authors argue [10]-[12] that exposure of water to the magnetic field can improve the mechanical properties of a cementitious composite.

It is important to mention that the research presented in this paper is a preliminary study to explore if the magnetic orientation of steel fibres in cementitious composites is even possible and additionally on which parameters it depends.

\section{TECHNICAL BACKGROUND}

The magnetic orientation of the fibres will depend mainly on the shape of the magnetic field, i.e., on the direction of the magnetic field lines. An important parameter for the magnetic fibre orientation is the velocity of the passage of the mixture through the magnetic field, which is the time required for the complete desired orientation of the fibres. At the same time, the intensity of the magnetic field must be sufficient enough to overcome the resistance of the cementitious matrix, which is governed by its viscosity.

Magnetic induction measurements were performed by using a standard gauss meter before and after exposure to the magnetic field. Magnetic induction for the post-production state, i.e. before exposure to the magnetic field was determined to be $0.04 \mathrm{mT}$. This very small value may be a consequence of the Earth's magnetic field and for the mixture, this value can be considered as nil. Thereafter, the fibres were exposed to a magnetic field of $44 \mathrm{mT}$ and the measurement was repeated after removal from this field. The induction that was measured near the fibres was determined to be around $1.16 \mathrm{mT}$, which demonstrated the residual remanence of the fibres.

Another issue that is related to the remanence is the clustering of the fibres. Each ferromagnetic fibre behaves like a small magnet after magnetization. Therefore, fibres could begin to attract each other and cluster together, which would be undesirable for our purposes. This behaviour depends on the material from which the ferromagnetic fibre is made of. Besides, a larger volume of fibres could produce a magnetic field around the resulting structure when the fibres inherit some of the magnetic properties.

In our measurements, the residual remanence value was much lower than expected. Therefore, it should not significantly affect the use of structures made from composites with magnetically oriented fibres. It was also found that the fibres tend to chain after magnetization due to its slight residual remanence.

The permeability of the cementitious matrix without ferromagnetic filler is similar to the permeability of the vacuum, and the magnetic properties of the sample will be affected primarily by the content and orientation of the fibres. If the fibres are oriented in the direction of the magnetic field, the effective permeability is maximal. If they are oriented perpendicular to the electromagnetic field lines, the effective permeability is minimal [7], [10].

\section{MATERIALS AND METHODS}

Magnetic orientation was achieved by placing the ferromagnetic material into the magnetic field, where the ferromagnetic steel fibres were magnetized. After magnetization, the fibre behaves like a small magnet and tends to orient in the direction of the lines of the magnetic field to which they are exposed. It is important to mention that the viscosity of the mixture must be well-tuned together with the power of the magnetic field, so the fibre can overcome the resistance of the matrix to be properly oriented. 
Three basic aspects have to be taken into account for fibres orientation. These are the velocity of the sample that is being pulled through the magnetic field, the intensity of the magnetic field and the viscosity of the sample. Device for fibre orientation was constructed to ensure smooth movement of the sample through a magnetic field to address those aspects.

Both cementitious composites and ultrasound gel were tested as a medium for fibre dispersion and orientation. The ultrasound gel was chosen as a suitable tool to substitute a cementitious matrix due to its transparency, which allows observing the orientation of the fibres. The level of agreement of the rheological properties of the ultrasound gel and the cementitious matrix was found to be sufficient in [13] and this assumption was also used in the framework this study.

Viscosity has a significant effect on the final fibre orientation [14]. The viscosity values of the cementitious matrix are ranging from $68 \mathrm{~Pa} \cdot \mathrm{s}$ to $530 \mathrm{~Pa} \cdot \mathrm{s}$ according to [6] and the viscosity values of the ultrasound gel are ranging from $60 \mathrm{~Pa} \cdot \mathrm{s}$ to $80 \mathrm{~Pa} \cdot \mathrm{s}$, based on data from the manufacturer. Steel microfibers were added into the ultrasound gel solution as well as into the cementitious mixture. High-strength fibres used in the framework of this study were straight and smooth. The fibres were $13 \mathrm{~mm}$ in length and $0.15 \mathrm{~mm}$ in diameter. The tensile strength of the fibres is $2,800 \mathrm{MPa}$, as specified by the manufacturer.

\subsection{Fibre orientation in ultrasound gel}

By using a non-magnetic screw with a motor, the sample was carried through a magnetic field formed by a set of magnets. The set of magnets consists of two ferrite rings and eight neodymium magnets (Fig. 1). The set of magnets was supposed to generate a magnetic field that is very similar to the magnetic field generated by an electric coil. By changing the number of neodymium magnets it was possible to modulate the magnetic induction in the area where the trays with samples were moving. The permanent magnets have been used instead of a coil for their simplicity, durability and because there was no need for a power supply.
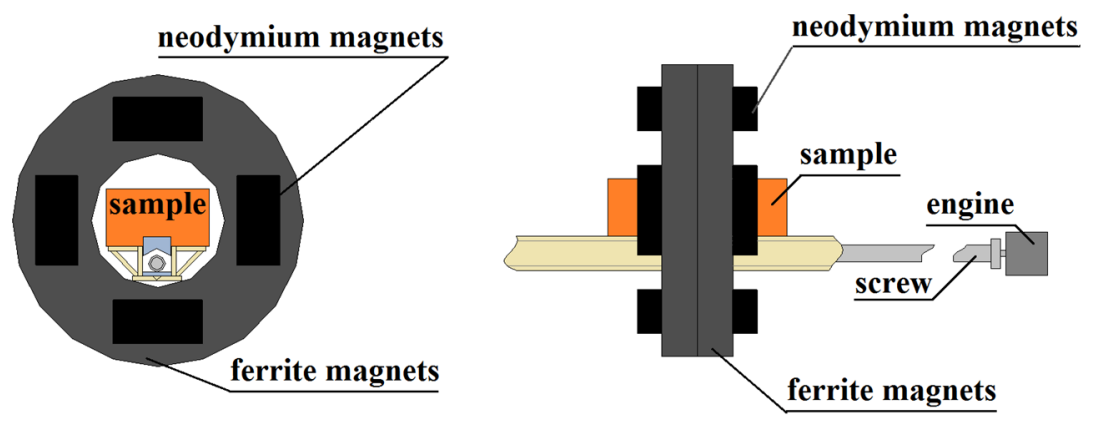

Figure 1: Schema of ferrite rings with neodymium magnets: front view and side view.

The given set of magnets - a ferrite rings with added neodymium magnets (Fig. 1) creates a magnetic field that closely resembles the shape of the magnetic field made by a powered coil.

The equipment (Fig. 2) was created from materials available in the workplace, i.e. ferrite rings with added neodymium magnets. The disadvantage of the presented solution is the limited size of the sample given by the inner diameter of the ferrite ring, which is determined by the fact that the element has to be carried through the ring. 


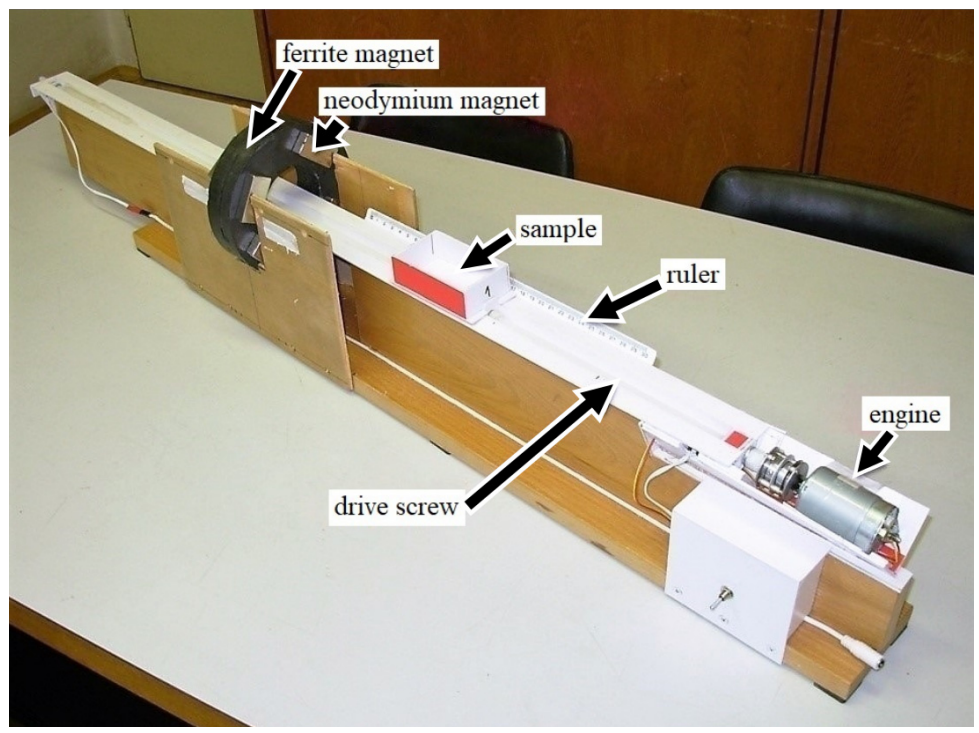

Figure 2: Realization of ferrite rings with neodymium magnets.

Table 1: Results of the first experimental phase.

\begin{tabular}{|c|c|c|c|c|c|}
\hline Series & $\begin{array}{l}\text { Ultrasound gel: } \\
\text { Water }\end{array}$ & $\begin{array}{l}\text { Viscosity } \\
(\mathrm{Pa} \cdot \mathrm{s})\end{array}$ & $\begin{array}{l}\text { Intensity of the } \\
\text { magnetic field } \\
\text { (mT) }\end{array}$ & $\begin{array}{l}\text { Velocity } \\
(\mathrm{mm} / \mathrm{s})\end{array}$ & $\begin{array}{l}\text { Degree of the } \\
\text { fibre orientation }\end{array}$ \\
\hline \multirow{4}{*}{1} & \multirow{4}{*}{$1: 0$} & \multirow{4}{*}{452.4} & 55 & 20 & 1 \\
\hline & & & 55 & 33.3 & 1 \\
\hline & & & 30 & 40 & $4-5$ \\
\hline & & & 55 & 100 & 4 \\
\hline \multirow{5}{*}{2} & \multirow{5}{*}{$1: 0.566$} & \multirow{5}{*}{371.2} & 55 & 20 & 1 \\
\hline & & & 30 & 20 & $3-4$ \\
\hline & & & $40-50$ & 20 & 3 \\
\hline & & & 55 & 33.3 & 1 \\
\hline & & & 55 & 26.6 & 2 \\
\hline \multirow{4}{*}{3} & \multirow{4}{*}{$1: 0.35$} & \multirow{4}{*}{382.4} & 55 & 20 & 1 \\
\hline & & & 55 & 40 & 3 \\
\hline & & & 55 & 20 & 2 \\
\hline & & & 55 & 40 & $2-3$ \\
\hline \multirow{3}{*}{4} & \multirow{3}{*}{$1: 0.15$} & \multirow{3}{*}{380.8} & 55 & 20 & 1 \\
\hline & & & 55 & 20 & $1-2$ \\
\hline & & & 55 & 20 & 1 \\
\hline
\end{tabular}

The velocity of the sample passing through the magnet was controlled by the motor. The velocity of the passage was determined from the camera, which captured each passage of the specimen through the magnetic field. Four different samples were used for the experiment (Table 1), all of them with the same volumetric content of fibres, which was $1.5 \%$. The samples varied in the water content with which the ultrasound gel was diluted. A ratio of 
1:0.566 (ultrasound gel-to-water) was used for the comparable viscosity values with the cementitious matrix [13]. A ratio of 1:0 corresponds to the undiluted ultrasound gel. The fibre orientation was also examined on the other two ultrasound gel-to-water ratios chosen between these two previously mentioned. For all samples, the viscosity was measured using a rotational viscometer, type Brookfield DV-II + Pro, on fibre-free samples. By using this viscometer, it is possible to measure relative values only and therefore it can only be use for comparative measurement. It cannot be compared with the absolute values from other authors [6]. Values are shown only for comparison of samples with each other. Comparative measurements of ultrasound gel and cement matrix were not performed, and the assumption of similar values of the viscosity is based on results presented in [13].

The resulting samples with fibres were placed in a tray with dimensions of $45 \times 75 \times 23 \mathrm{~mm}$ (Fig. 3) and moved through the magnetic field by the specific velocity. The degree of the fibre orientation was monitored in relation to the intensity of the magnetic field and the velocity of the tray.

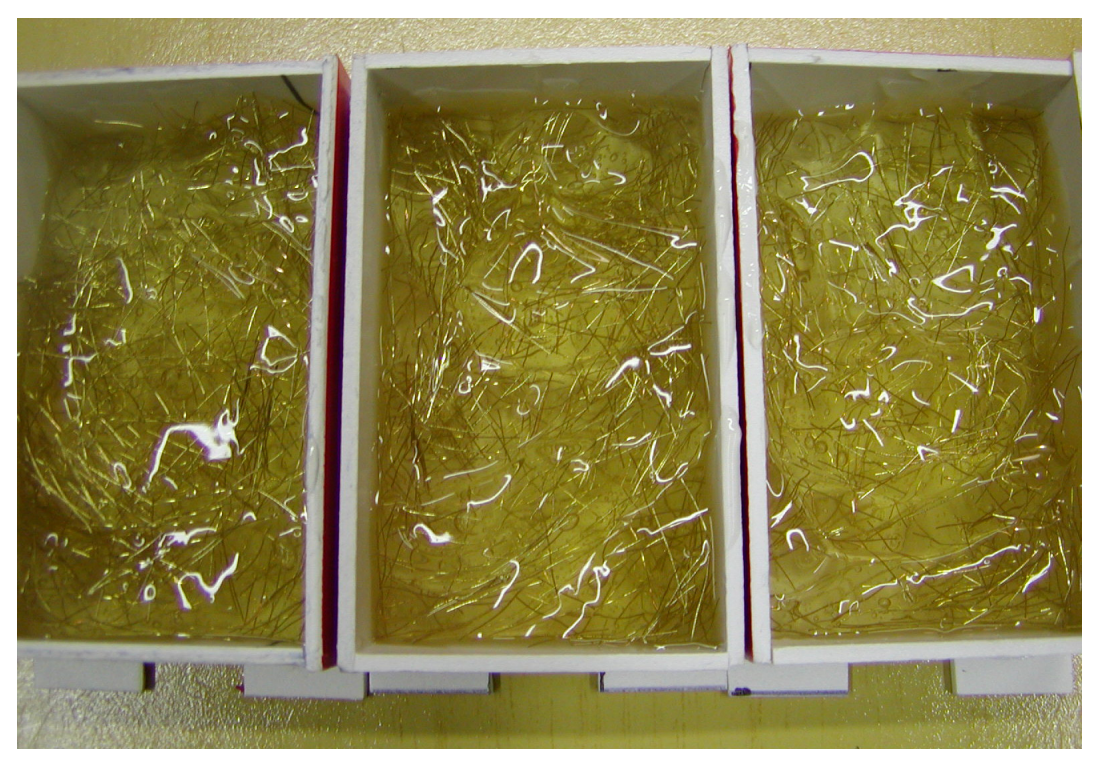

Figure 3: Prepared non-oriented samples (before passing through the magnetic field).

The position of the fibres was evaluated relative to the axis of the magnetic field (identical to the axis of the motion) on the 5-degree scale. A position of the fibre arrangement within $\pm 30^{\circ}$ from the axis of movement was classified by mark 1 . If the configuration of the fibres was practically unchanged during the passage through the magnetic field, the degree of arrangement (orientation) of fibres was classified by the mark 5 .

The result of the first experiment confirmed the expectations, that the magnetic orientation of the steel fibres depends on the velocity, viscosity and intensity of the magnetic field. The most optimal velocity for complete orientation (classification mark 1), that was found to be on safe side was $20 \mathrm{~mm} / \mathrm{s}$. The average field strength of $30 \mathrm{mT}$ was achieved by using ferrite magnets. The set of ferrite rings and 4 neodymium magnets can induce field with intensity ranging from $40 \mathrm{mT}$ to $50 \mathrm{mT}$. However, both of these assemblies have proved to be insufficient to orient the fibres in any sample of different viscosity. The intensity of a 
magnetic field of $55 \mathrm{mT}$ was the maximum intensity for complete orientation, classified as 1 , sufficient for orientation of the samples with the highest viscosity $(452.4 \mathrm{~Pa} \cdot \mathrm{s})$. This magnitude of magnetic induction was achieved by a set consisting of a complete set of ferrite rings and eight neodymium magnets. The comparison of samples before and after magnetic orientation is showed in Fig. 4.
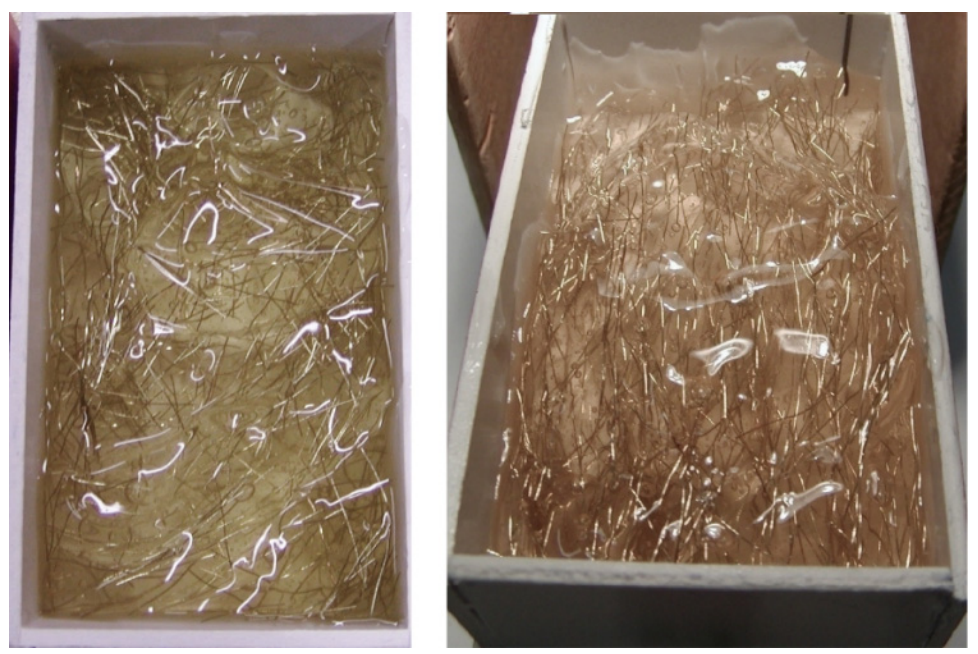

Figure 4: Comparison of non-oriented (left) and oriented (right) sample, classified as 1.

\subsection{Fibre orientation in cementitious composite}

It was determined that the ferrite rings with neodymium magnets used in the experiment with ultrasound gel were a reasonable option for the directed magnetic orientation of fibres. The decision is based on the visual observation of ultrasound gel with fibres after passing through various magnet systems with various magnetic field shapes. The ferrite rings with neodymium magnets were additionally supplemented with another eight neodymium magnets N38 measuring $25 \times 25 \times 10 \mathrm{~mm}$ to increase the intensity of the magnetic field (Fig. 5) to be on the safe side for proper fibre orientation. The intensity of the magnetic field was now determined to be $60 \mathrm{mT}$.

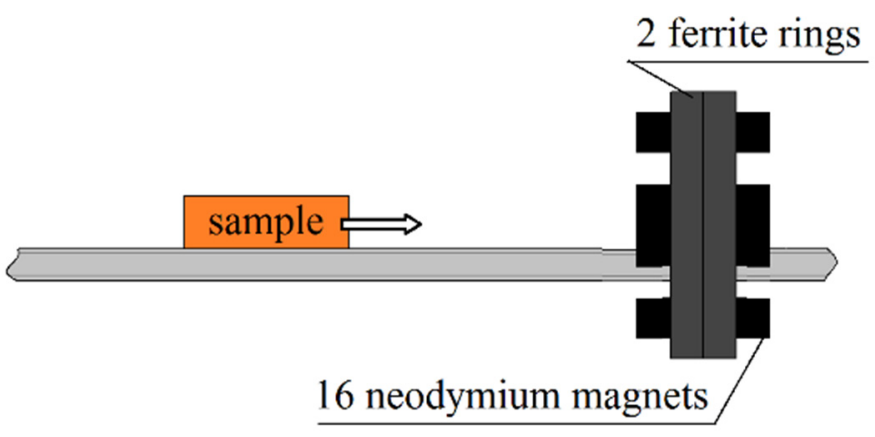

Figure 5: Schema of the prototype device with two ferrite rings and 16 neodymium magnets. 


\subsubsection{Production of samples}

The cementitious matrix used in the framework of this study is consisting of fine-grained aggregate with fraction up to $1 \mathrm{~mm}$, cement, silica fume, glass powder, water, and high-range water-reducers, fully described in [15]-[17] (Table 2). The components were mixed in a $750 \mathrm{~kg}$ mixer and transported into the lab in $12 \mathrm{~kg}$ bags as a dry prefabricated mixture. The dry prefabricated mixture was supplemented with tap water. The amount of water was $10 \%$ of the dry mixture's weight. Fibres were added during mixing in a volume of $1.5 \%$ and $0.75 \%$ (Table 3). Indirect non-destructive methods were employed to verify the fibre orientation.

Table 2: Composition of the dry prefabricated mixture: Amount expressed as multiples of binder component weight unit.

\begin{tabular}{|c|l|}
\hline Proportions by weight & Components of the dry prefabricated mixture \\
\hline 1 & CEM 42.5 \\
\hline 0.1 & Amorphous $\mathrm{SiO}_{2}$, microsilica \\
\hline 0.25 & Silica fume with a medium grain size of $6 \mu \mathrm{m}$ \\
\hline \multirow{2}{*}{1.6} & $\begin{array}{l}\text { Pure silica sand with a continuous granulometry of } 0.1 \text { to } \\
1.2 \text { mm with a medium grain size of } \mathrm{d}_{50}=500 \mu \mathrm{m}\end{array}$ \\
\hline 0.01 & Superplasticizer - high-range water-reducer \\
\hline 0.001 & Antifoaming additive \\
\hline
\end{tabular}

Table 3: Weights for the production of the sample with $1.5 \%$ of fibre volume content.

\begin{tabular}{|l|c|}
\hline Component & Weight $(\mathrm{g})$ \\
\hline Dry prefabricated mixture & 625 \\
\hline Water & 61 \\
\hline Fibres $(13 \mathrm{~mm}, \varnothing 0.15 \mathrm{~mm})$ & 35 \\
\hline
\end{tabular}

The size of the specimen was $40 \times 40 \times 160 \mathrm{~mm}$. The specimen size of $40 \times 40 \times 160 \mathrm{~mm}$ is also the maximum sample size that can be used for magnetic orientation of fibres in the magnet system with ferrite rings.

The mixture with fibres was filled into the formwork made of non-magnetic material. The fibres in the sample were then oriented in the desired direction, identical to the direction of movement of the sample. The fibre orientation was subsequently verified by measuring the electrical parameters of the coil (explained in the following text) and using CT scans (X-ray diagnostics).

\subsubsection{Measurement of fibre orientation using the coil quality factor $\mathrm{Q}$}

The degree of the fibre orientation was determined using a measuring coil. The samples were placed in the coil and the quality factor Q was measured. It has been presumed, that for samples with more oriented fibres, there will be a significant decrease in the quality factor Q.

The properties of a coil are given by its shape, the number of turns, wire diameter, wire material, coil core, voltage and current to be supplied and its frequency. One way to measure the characteristics of the coil is through the coil quality factor. The quality factor Q was measured using an impedance meter (Agilent E4991A). Measurements were made using 27 coil turns made of copper wire with a diameter of $1.8 \mathrm{~mm}$ and with a frequency ranging from $1 \mathrm{MHz}$ to $3 \mathrm{MHz}$. 
The samples were placed in a measuring coil as the coil core. The coil core, i.e. the cementitious sample with steel fibres was monitored during the measurement to determine the coil quality factor. It has been confirmed that the coil quality factor decreases with the desired orientation of the fibres. It has also been verified that the permeability of a plain cementitious matrix or plain ultrasound gel is practically the same as the permeability of the air. This means that the quality factor will not change significantly with the placement of the plain cementitious composite or ultrasound gel into the coil.

The measurements were made on the sides (beginning and end) and in the middle of the specimen. The beginning and the end of the specimens are considered in the direction of movement of the sample through the magnet system. During the measurement, it was found that the fibre volume content was lower at the beginning of the sample than at the end. This phenomenon is caused by forces, which attract the fibres back to themselves after passing the sample through the magnet system. The measurement confirmed the applicability of this method for comparative measurement of the degree of orientation of the fibres in the samples. Unlike other works [18], [19], where the same method was used but different parameter was measured; the measurement of quality factor Q proved to be more suitable and more sensitive.

At first, the measurement was performed on specimens with an ultrasound gel. A decrease of the coil quality factor $\mathrm{Q}$ for the oriented state of the fibres was verified by the measurement (measured in the direction of the fibres). Finally, the measurements were conducted on the concrete samples, where considerable dependence of the fibre orientation on the quality factor of the coil Q was again confirmed. The age of the concrete has no significant influence on the measured results.

The difference of decline in quality factor between the non-orientated and orientated state was greater for the fibre content $0.75 \%$ than for the $1.5 \%$ content of fibres (Fig. 6). This fact can be explained by the limitation of the movement of the individual fibres in the larger volumes of fibres. Therefore, the orientation works better for the sample containing fewer fibres than samples with larger volumes of fibres.
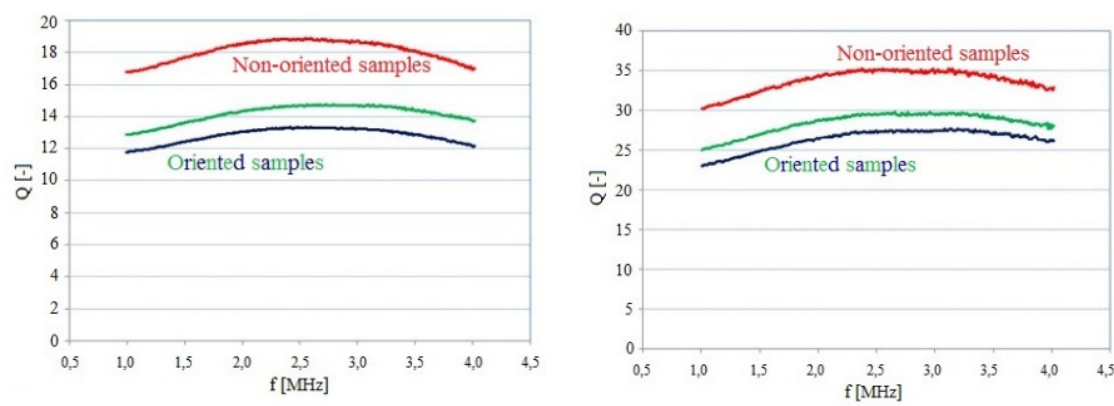

Figure 6: Quality factor for cement matrix with $1.5 \%$ (left) and $0.75 \%$ (right) of fibre volume content.

\subsubsection{CT-scans}

The orientation of fibres in cementitious samples was further verified by X-ray diagnostics at the CTU in Prague. The samples were scanned in the form of a 3D matrix processed by the computer tomography method in the "myVGL2.2" software. This method was used as a 
reference for verification of the fibre orientation and validation of the results gained by measuring electromagnetic properties.

The samples were scanned at the beginning, middle and end of the volume. The size of the scan area was $40 \times 40 \times 40 \mathrm{~mm}$. Resolution of the spatial image was $1000 \times 1000 \times 1000$ pixels. For non-oriented specimens, only the middle parts of the samples were scanned. The difference between the non-oriented and the oriented specimen is visible from CT-Scan in Figs 7 and 8.

From the CT-scans it can be stated that exposure of the cementitious composite to a magnetic field can effectively help to a controlled orientation of the fibres in the cementitious composite. The apparent orientation can be observed for both samples with different fibre volume content of fibres, i.e. $1.5 \%$ of fibres by volume (Fig. 7 ) and $0.75 \%$ of fibres by volume (Fig. 8). Mutual comparison of non-oriented and oriented fibres is presented for each case of fibre volume fraction.
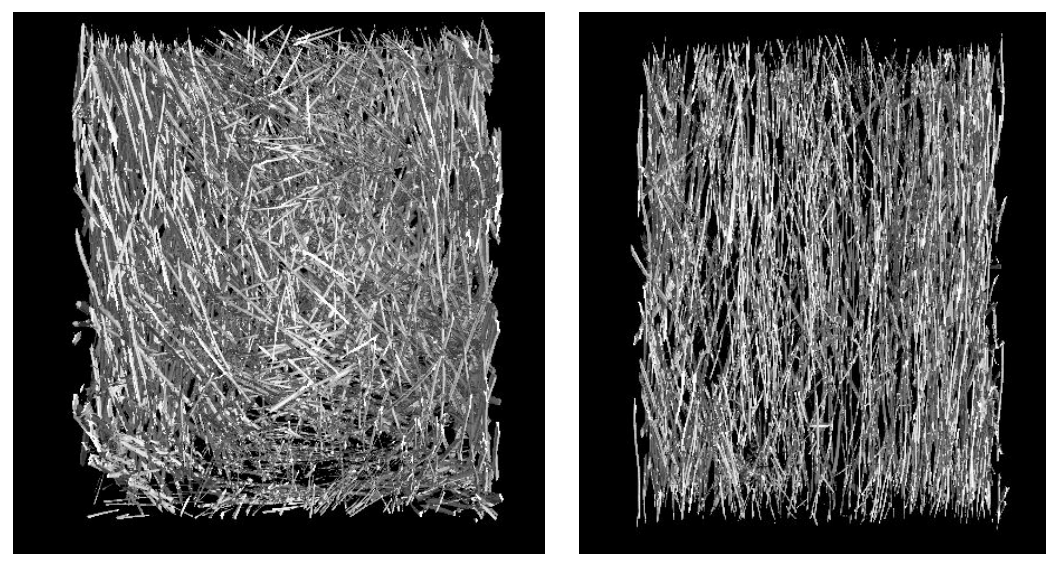

Figure 7: Cross-section of the CT scan of the sample with $1.5 \%$ of fibres by volume; nonoriented (left) and oriented (right) fibres.
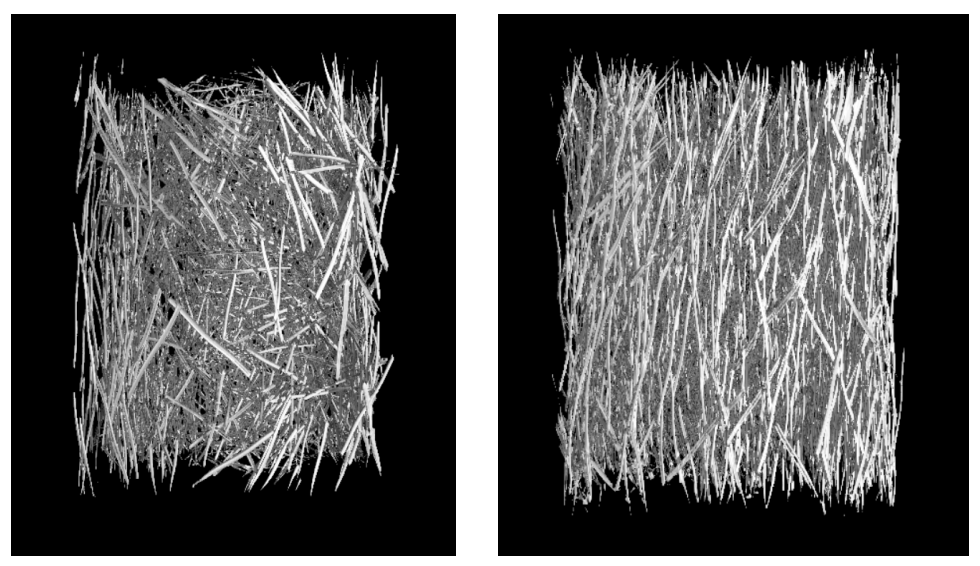

Figure 8: Cross-section of the CT scan of the sample with $0.75 \%$ of fibres by volume; nonoriented (left) and oriented (right) fibres. 


\section{CONCLUSIONS AND FURTHER OUTLOOK}

The paper aims to describe the directed orientation of steel fibres in ultrasound gel and cementitious matrix using a magnetic field. The electromagnetic principles and X-ray imaging were employed for measurement and evaluation of orientation of fibres. The ferrite rings with neodymium magnets have been evaluated as a reasonable option for fibre orientation. Measurement of the effect of the fibre orientation on the electromagnetic properties, especially the change of inductance, was supplemented by the measurement of the coil quality factor. The sensitivity of this parameter to the orientation of the ferromagnetic fibres has demonstrated the benefits of its use. The validation of the fibre orientation results and the measurement methods was conclusively confirmed through the CT-scanning.

It was found that it is possible to orient the steel fibres in cementitious composite although residual remanence of steel fibres has been observed. However, the measured values are reasonably small to not affect the structures made of fibres that were exposed to the electromagnetic field. The study additionally confirmed the dependence of the orientation of the steel fibres on the intensity of the magnetic field, on the viscosity of the environment where the fibres are located, and on the velocity of the sample passing through the magnetic field. The minimum magnetic field intensity recommended for the orientation of the steel fibres in an undiluted ultrasound gel with a viscosity of $452.4 \mathrm{~Pa} \cdot \mathrm{s}$ was set to be $55 \mathrm{mT}$ and the optimal velocity was found to be $20 \mathrm{~mm} / \mathrm{s}$. In the framework of this study, the intensity of the magnetic field was $60 \mathrm{mT}$, which led to the successful orientation of the fibres in the cementitious composite, however, it is necessary to further investigate this parameter.

\section{ACKNOWLEDGEMENTS}

The authors gratefully acknowledge the financial support from the Czech Science Foundation (grant number GA20-00624S). The authors also acknowledge assistance from students and technical staff at the Experimental Centre of the CTU who participated in the project (project no. SGS19/143/OHK1/3T/11 and SGS20/054/OHK1/1T/11).

\section{REFERENCES}

[1] Afroughsabet, V., Biolzi, L. \& Ozbakkaloglu, T., High-performance fiber-reinforced concrete: A review. Journal of Materials Science, 51, pp. 6517-6551, 2016. DOI: $10.1007 / \mathrm{s} 10853-016-9917-4$.

[2] Yoo, D.Y. \& Banthia, N., Mechanical properties of ultra-high-performance fiberreinforced concrete: A review. Cement and Concrete Composites, 73, pp. 267-280, 2016. DOI: 10.1016/j.cemconcomp.2016.08.001.

[3] Nicolaides, D., Kanellopoulos, A., Savva, P. \& Petrou, M., Experimental field investigation of impact and blast load resistance of ultra high performance fibre reinforced cementitious composites (UHPFRCCs). Construction and Building Materials, 95, pp. 566-574, 2015. DOI: 10.1016/j.conbuildmat.2015.07.141.

[4] Nicolaides, D., Kanellopoulos, A., Petrou, M., Savva, P. \& Mina, A., Development of a new ultra high performance fibre reinforced cementitious composite (UHPFRCC) for impact and blast protection of structures. Construction and Building Materials, 95, pp. 667-674, 2015. DOI: 10.1016/j.conbuildmat.2015.07.136.

[5] Yoo, D.-Y., Kang, S.-T. \& Yoon, Y.-S., Effect of fiber length and placement method on flexural behavior, tension-softening curve, and fiber distribution characteristics of UHPFRC. Construction and Building Materials, 64, pp. 67-81, 2014.

DOI: 10.1016/j.conbuildmat.2014.04.007. 
[6] Lovichova, R., Fornusek, J., Mara, M., Kocova, M. \& Rihova, Z., The fibre orientation influence in cementitious composite against extreme load resistance. IOP Conference Series: Materials Science and Engineering, 307, 012069, 2018. DOI: 10.1088/1757899X/307/1/012069.

[7] Fornůsek, J. \& Tvarog, M., Influence of casting direction on fracture energy of fiberreinforced cement composites. Key Engineering Materials, 594, pp. 444-448, 2014. DOI: 10.4028/www.scientific.net/KEM.594-595.444.

[8] Lovichová, R., Mára, M. \& Fornůsek, J., Projectile impact resistance of UHPFRC structures for various methods of fresh mixture placement. Procedia Engineering, 193, pp. 80-87, 2017. DOI: 10.1016/J.PROENG.2017.06.189.

[9] Stiel, T., Karihaloo, B.L. \& Fehling, E., Effect of casting direction on the mechanical properties of CARDIFRC. Proceedings of the International Symposium on Ultra High Performance Concrete (UHPC), pp. 481-493, 2004.

[10] Afshin, H., Gholizadeh, M. \& Khorshidi, N., Improving mechanical properties of high strength concrete by magnetic water technology. Scientia Iranica, 17, pp. 74-79, 2010.

[11] Su, N., Wu, Y.-H. \& Mar, C.-Y., Effect of magnetic water on the engineering properties of concrete containing granulated blast-furnace slag. Cement and Concrete Research, 30(4), pp. 599-605, 2000. DOI: 10.1016/S0008-8846(00)00215-5.

[12] Gholizadeh, M. \& Arabshahi, H., The effect of magnetic water on strength parameters of concrete. Research Journal of Applied Sciences, 6(1), pp. 66-69, 2011.

DOI: 10.3923/rjasci.2011.66.69.

[13] Lovichova, R., Fornůsek, J., Soukupová, L. \& Valentin, J., Ultrasound gel as suitable tool for simulation of the fibre orientation in the fibre reinforced concrete. Exp. Stress. Anal., pp. 1-4, 2016.

[14] Boulekbache, B., Hamrat, M., Chemrouk, M. \& Amziane, S., Flowability of fibrereinforced concrete and its effect on the mechanical properties of the material. Construction and Building Materials, 24, pp. 1664-1671, 2010.

DOI: 10.1016/J.CONBUILDMAT.2010.02.025.

[15] Bažantová, Z., Kolář, K., Konvalinka, P. \& Litoš, J., Multi-functional highperformance cement based composite. Key Engineering Materials, 677, pp. 53-56, 2016. DOI: 10.4028/www.scientific.net/KEM.677.53.

[16] Kolář, K., Litoš, J., Bažantová, Z. \& Reiterman, P., Measurement of volume changes of high performance cement based composites. Applied Mechanics and Materials, 827, pp. 328-331, 2016. DOI: 10.4028/www.scientific.net/AMM.827.328.

[17] Bažantová, Z., Kolář, K., Konvalinka, P., Litoš, J. \& Petrtýl, M., Controlled hardening of silicate binders for the optimization of high performance composites. Key Engineering Materials, 722, pp. 281-285, 2016.

DOI: 10.4028/www.scientific.net/KEM.722.281.

[18] Ozyurt, N., Woo, L.Y., Mason, T.O. \& Shah, S.P., Monitoring fiber dispersion in fiberreinforced cementitious materials: Comparison of AC-impedance spectroscopy and image analysis. ACI Materials Journal, 103(5), pp. 340-347, 2006.

DOI: $10.14359 / 18156$.

[19] Ozyurt, N., Mason, T.O. \& Shah, S.P., Non-destructive monitoring of fiber orientation using AC-IS: An industrial-scale application. Cement and Concrete Research, 36, pp. 1653-1660, 2006. DOI: 10.1016/J.CEMCONRES.2006.05.026. 